\title{
Awareness and Knowledge of Oral Cancer and Potentially Malignant Oral Disorders among Dental Patients in Far North Queensland, Australia
}

\author{
Joseph Formosa, Rachel Jenner, My-Duyen Nguyen-Thi, Caitlin Stephens, Corey \\ Wilson, Anura Ariyawardana*
}

\begin{abstract}
Background: Public awareness/knowledge on oral and pharyngeal cancer (OPC), potentially malignant disorders (PMODs) and their risk factors is crucial for prevention and early detection of OPC and PMODs. Yet, there are no published data available on the awareness and knowledge of OPC and PMODs among people living in Far North Queensland, Australia. Materials and Methods: This study was conducted as a cross sectional survey. A self-administered questionnaire was designed and consisted of relevant questions to ascertain socio-demographic information, awareness and knowledge of OPC, PMODs and risk factors and questions on participant's exposure to risk factors and dietary history were also included. Survey was carried out at the Dental Clinic of the James Cook University School of Dentistry (JCU Dental), Cairns, Australia. Subjects above the age of 20 years $(n=366)$ were randomly selected during the period from 31st July to 6th September 2013 and questionnaire was distributed to complete while they are waiting for treatment. Data analysis was carried out using SPSS version 21 and the chi -squared test was employed to compare groups. $P<0.05$ was considered statistically significant. Results: The study revealed that $52.3 \%$ of the respondents were aware of the existence of OPC but only $19.0 \%$ were aware of PMODs. Of those who were aware of oral cancer, $92 \%$ agreed or strongly agreed that smoking is a strong risk factor for OPC. Similarly a relatively high proportion of the respondents agreed or strongly agreed that tobacco chewing $(84 \%)$, tobacco chewing with areca nut $(68 \%)$, chewing areca nut alone $(51 \%)$ and exposure to actinic radiation $(\mathbf{7 1 \%})$ as risk factors. However, the results for alcohol intake, age, and HPV infection were found to be relatively poor with proportions $33 \%, 34 \%$, and $23 \%$ respectively. Conclusions: This study revealed an alarming lack of awareness and knowledge of OPC and PMODs.
\end{abstract}

Keywords: Oral cancer - potentially malignant oral disorders - awareness - far north Australia

Asian Pac J Cancer Prev, 16 (10), 4429-4434

\section{Introduction}

Globally, cancer is considered a serious public health problem with increasing number of cancer patients reported each year. GLOBOCAN, has estimated 14.1 million new cancer cases and 8.2 million cancer-related deaths in 2012 (Ferlay et al., 2013) compared to 12.7 million and 7.6 million, respectively, in 2008 (Ferlay et al., 2018). In 2012, lip and oral cavity cancers and pharyngeal cancers (excluding nasopharynx) were estimated to be 300,373 , and 142,387 , representing $2.1 \%$ and $1.0 \%$ of all new cancers respectively (Ferlay et al., 2013). In Australia, 42,671 deaths were due to cancer which accounts for $29 \%$ of all deaths in 2011. Of these oral and pharyngeal cancers excluding cancers of salivary glands (C07 and C08), nasopharynx (C11), phyriform sinus (C12) and hypo-pharynx (C13) accounted for 1.2\% (Australian Beaurau of Statistics. Available at: http://www.abs.gov.
au/AUSSTATS/abs@.nsf/DetailsPage/3303.02011?Ope nDocument).

Recent trends have shown a decline in the incidence of lip and oral cavity cancers in Australia (Ariyawardana and Johnson, 2013). This decline is in line with the decline in trends of tobacco and alcohol consumption (OECD, 2011). This reflects the increasing awareness on the effects of tobacco and alcohol use and its impacts on oral cancer and other health related problems. Although the recent decline in oral cancer incidence is encouraging, it is still relatively high compared to the rest of the world. Moreover, it has been shown that HPV related pharyngeal cancers are on the rise in Australia (Ariyawardana and Johnson, 2013) consistent with some countries in the world (Marur et al., 2010).

Although, it is generally believed that the 5-year survival has not been improved over the years despite the advancement in treatment and rehabilitation (Bettendorf 
Joseph Formosa et al

et al., 2004) some recent studies have shown encouraging results with improvement in overall 5-year survival rates (Chandu et al., 2005; Rogers et al., 2009; Zini et al., 2010). The best 5-year survival has been reported for lip cancers (Zini et al., 2010). In general survival rates decline with the advancement of the stage of the disease in which TNM stages I and II have comparatively higher survival rate than stages II and IV (Sargaran et al., 2008; Warnakulasuriya, 2009).

Many patients who have undergone successful treatment for oral cancer may have to face some functional and cosmetic impairment that includes difficulties in eating, swallowing, speaking and disfigurement. This may have significant adverse impact on their quality of life (Chandu et al., 2006). The detection of oral cancer at an early stage of the disease is the most effective means of improving survival as well as the morbidity, disfigurement and even the associated health care costs (Scott et al., 2008; Rogers et al., 2009). Lack of public awareness or knowledge and the asymptomatic nature of early disease prevent patients seeking treatment at the early stages of the disease (Scott et al., 2008).

To the best of our knowledge, no work has yet been published in relation to the knowledge/awareness of OPC and PMODs among the population in far north Queensland (FNQ) Australia. Therefore, the primary aim of this study was to assess the awareness and knowledge of oral and pharyngeal cancers and "potentially malignant oral disorders" and their risk factors among hospital attending patients in FNQ.

\section{Materials and Methods}

In order to assess the awareness of OPC, PMODs and their associated risk factors, a self-administered questionnaire was designed. The questionnaire consisted of three sections with relevant questions to ascertain sociodemographic information, awareness and knowledge of OPC, PMODs and risk factors and questions on participant's exposure to risk factors and dietary history

Table 1. Socio Demographic Data of Survey Respondents $(\mathbf{n}=300)$

\begin{tabular}{llcc}
\hline & & Number & $\%$ \\
\hline \multirow{4}{*}{ Agender } & Male & 138 & 46 \\
& Female & 162 & 54 \\
& $20-29$ & 48 & 16 \\
& $30-39$ & 40 & 13.3 \\
$40-49$ & 59 & 19.8 \\
$50-59$ & 70 & 23.3 \\
$60-69$ & 52 & 17.3 \\
$70-79$ & 27 & 9 \\
$80+$ & 4 & 1.3 \\
Level of education & & \\
No school education & 1 & 0.3 \\
& Primary school & 8 & 2.7 \\
& Secondary school & 134 & 44.7 \\
Diploma / trade certificate & 104 & 34.7 \\
Bachelor's degree & 37 & 12.3 \\
& Postgraduate degree & 16 & 5.3 \\
Experience as a patient at the Dental School & & \\
& Yes & 135 & 45 \\
No & 165 & 55 \\
\hline
\end{tabular}

Table 2. Awareness of OPC with Different Demographic Parameters

\begin{tabular}{|c|c|c|c|c|c|c|c|}
\hline & & \multicolumn{2}{|c|}{ Aware } & \multicolumn{2}{|c|}{ Not aware } & \multirow[t]{2}{*}{$\mathrm{X}^{2}$} & \multirow[t]{2}{*}{$\mathrm{p}$} \\
\hline & & $\mathrm{n}$ & $\%$ & $\mathrm{n}$ & $\%$ & & \\
\hline \multirow[t]{2}{*}{ Gender } & Male & 67 & 48.6 & 71 & 51.4 & & \\
\hline & Female & 90 & 55.6 & 72 & 44.4 & 1.466 & 0.226 \\
\hline \multirow[t]{3}{*}{ Age } & $20-39$ & 54 & 61.4 & 34 & 38.6 & & \\
\hline & $40-59$ & 70 & 54.3 & 59 & 45.7 & & \\
\hline & $>60$ & 33 & 39.8 & 50 & 60.2 & 8.33 & 0.160 \\
\hline \multirow[t]{3}{*}{ Level of education } & No or up to primary & 2 & 22.2 & 7 & 77.8 & & \\
\hline & Secondary school & 61 & 45.8 & 73 & 54.5 & & \\
\hline & Tertiary education & 94 & 59.9 & 63 & 40.1 & 9.34 & 0.009 \\
\hline \multicolumn{8}{|c|}{ Experience as a patient at the Dental School } \\
\hline & yes & 75 & 55.6 & 60 & 44.4 & & \\
\hline & no & 82 & 49.7 & 83 & 50.3 & 1.022 & 0.321 \\
\hline
\end{tabular}

Table 3. Awareness on PMODs with different Demographic Parameters

\begin{tabular}{|c|c|c|c|c|c|c|c|}
\hline & & \multicolumn{2}{|c|}{ Aware } & \multicolumn{2}{|c|}{ Not aware } & \multirow[t]{2}{*}{$\mathrm{X}^{2}$} & \multirow[t]{2}{*}{$\mathrm{p}$} \\
\hline & & $\mathrm{n}$ & $\%$ & $\mathrm{n}$ & $\%$ & & \\
\hline \multirow[t]{2}{*}{ Gender } & Male & 22 & 15.9 & 116 & 84.1 & & \\
\hline & Female & 35 & 21.6 & 127 & 78.4 & 1.55 & 0.213 \\
\hline \multirow[t]{3}{*}{ Age } & $20-39$ & 16 & 18.2 & 72 & 81.8 & & \\
\hline & $40-59$ & 26 & 20.2 & 103 & 79.8 & & \\
\hline & $>60$ & 15 & 18.1 & 68 & 81.9 & 0.19 & 0.906 \\
\hline \multicolumn{8}{|c|}{ Level of education } \\
\hline & No or up to primary & 1 & 11.1 & 8 & 88.9 & & \\
\hline & Secondary school & 22 & 16.4 & 112 & 83.6 & & \\
\hline & Tertiary education & 34 & 21.7 & 123 & 78.3 & 1.66 & 0.435 \\
\hline \multicolumn{8}{|c|}{ Experience as a patient at the Dental School } \\
\hline & yes & 37 & 27.4 & 98 & 72.6 & & \\
\hline & no & 20 & 12.1 & 145 & 87.9 & 11.27 & 0.001 \\
\hline
\end{tabular}


Awareness and Knowledge of Oral Cancer and Potentially Malignant Oral Disorders among Dental Patients in Queensland

were also included. The survey was carried out at the Dental Clinic of the James Cook University School of Dentistry (JCU Dental), Cairns, Australia. Subjects above the age of 20 years $(n=366)$ were randomly selected during the period from 31st July to 6th September 2013. Questionnaires were distributed among dental patients by the authors to complete while they are waiting for treatment. Verbal consent was obtained from all participants prior to the administration of the questionnaire and an information sheet was also provided. Patients who were below the age of 20 years and those who have literacy problems and non-English speaking individuals were excluded from the study. Ethics approval was obtained from the Human Research Ethics Committee, James Cook University, Australia. Data analysis was carried out using SPSS version 21 and the chi -squared test was employed to compare groups. P value $<0.05$ was considered statistically significant.

\section{Results}

Table 4. Sources of Information for PMODs and Oral Cancer Awareness

\begin{tabular}{lrrrr}
\hline & \multicolumn{2}{c}{ PMODs } & \multicolumn{2}{c}{ OPC } \\
& $\mathrm{n}$ & \multicolumn{1}{c}{$\%$} & $\mathrm{n}$ & $\%$ \\
\hline Family & 3 & 5.3 & 9 & 5.7 \\
Friends & 1 & 1.8 & 10 & 6.4 \\
Medical practitioner & 2 & 3.5 & 7 & 4.5 \\
Dentist & 16 & 28.1 & 21 & 13.4 \\
RN or Midwife & 5 & 8.8 & 3 & 1.9 \\
Mass Media & 30 & 52.6 & 105 & 66.8 \\
Total & 57 & 100.0 & 157 & 100.0 \\
\hline
\end{tabular}

A total of 366 questionnaires were distributed. Of these, 66 were excluded on the grounds of being incomplete and 300 questionnaires were then available for analysis. The study population consisted 162 female (54\%) and 138 male patients (46\%) with a median age bracket of 50-59. A summary of socio-demographic characteristics of respondents are summarized in table 1. In terms of education almost all the subjects (99.7\%) had some form of education. Of these over one half of the subjects $(52.3 \%)$ had tertiary education (Table 1$)$.

\section{Awareness of OPC/PMODs}

Just over half $(52.3 \%)$ of the respondents were aware that cancer could occur in the mouth and the gender did not influence the awareness $\left(X^{2}=1.466, \mathrm{p}=0.226\right)$. The awareness on oral cancer did not show significant difference across the age groups $\left(X^{2}=8.330, \mathrm{p}=0.160\right)$. The greatest awareness was found among the youngest age group 20-39 (61.4\%) while the lowest (39.8\%) was found among the respondents over the age of 60 years. The awareness on oral cancer has been found to increase with the increasing level of education and here the variation among different levels of education was statistically significant $\left(X^{2}=9.340, \mathrm{p}=0.009\right)$. However, there was no significant difference among those who have had and had not any previous experience at the school of dentistry dental clinic $\left(X^{2}=1.022, \mathrm{p}=0.321\right)$ (Table 2$)$.

Only $19.0 \%$ of the respondents were aware that PMODs could occur in the mouth. Gender $\left(X^{2}=1.553\right.$, $\mathrm{p}=0.213)$, age $\left(X^{2}=0.197, \mathrm{p}=0.906\right)$, and level of education $\left(X^{2}=1.664, \mathrm{p}=0.435\right)$ had no influence on this awareness (Table 3 ). In terms of the source of information for being aware of OPC and PMODs, the study found that mass

Table 5. Habit Status and Awareness of OPC and PMODs

\begin{tabular}{|c|c|c|c|c|c|c|c|}
\hline \multirow[t]{2}{*}{ Habit status } & & \multicolumn{3}{|c|}{ Awareness of OPC } & \multicolumn{3}{|c|}{ Awareness of PMODs } \\
\hline & & $\begin{array}{c}\text { Yes } \\
\mathrm{n}(\%)\end{array}$ & $\begin{array}{c}\text { No } \\
\mathrm{n}(\%) \\
\end{array}$ & $\begin{array}{c}\mathrm{P} \\
\left(\mathrm{X}^{2}\right)\end{array}$ & $\begin{array}{c}\text { Yes } \\
\mathrm{n}(\%)\end{array}$ & $\begin{array}{c}\text { No } \\
\mathrm{n}(\%) \\
\end{array}$ & $\begin{array}{c}\mathrm{P} \\
\left(\mathrm{X}^{2}\right) \\
\end{array}$ \\
\hline \multirow[t]{3}{*}{ Smoking } & Current & $44(57.9)$ & $32(42.1)$ & & $11(14.5)$ & $65(85.5)$ & \\
\hline & Ex-smoker & $58(53.2)$ & $51(46.8)$ & 0.384 (1.913) & $20(18.3)$ & $89(81.7)$ & 0.365 \\
\hline & Never smoked & $55(47.8)$ & $60(52.2)$ & & $26(22.6)$ & 89 (77.4) & -2.015 \\
\hline \multirow[t]{2}{*}{ Alcohol } & Consume & $114(53.5)$ & $99(46.5)$ & 0.519 & $37(17.4)$ & $176(82.6)$ & 0.26 \\
\hline & Do not consume & $43(49.4)$ & $44(50.6)$ & -0.415 & $20(23.0)$ & $67(77.0)$ & -1.267 \\
\hline
\end{tabular}

Table 6. Responses to Knowledge Questions on the Risk Factors and Clinical Presentation of Oral Cancer among those who Aware of OPC ( $=157)$

\begin{tabular}{|c|c|c|c|}
\hline & Statement & $\begin{array}{c}\text { Strongly agree/ } \\
\text { agree }\end{array}$ & $\begin{array}{c}\text { Strongly disagree/ } \\
\text { disagree/ unsure }\end{array}$ \\
\hline \multirow[t]{9}{*}{ Risk factors } & Tobacco smoking is associated with OPC & $144(92 \%)$ & $13(8 \%)$ \\
\hline & Tobacco chewing is associated with OPC & $132(84 \%)$ & $25(16 \%)$ \\
\hline & Tobacco chewing with areca nut is associated with OPC & $107(68 \%)$ & $50(32 \%)$ \\
\hline & Chewing areca nut is associated with OPC & $80(51 \%)$ & $77(49 \%)$ \\
\hline & Heavy Drinking of alcohol is associated with OPC & $52(33 \%)$ & $105(67 \%)$ \\
\hline & Actinic radiation is associated with $\mathrm{OPC}$ & $112(71 \%)$ & $45(29 \%)$ \\
\hline & Consumption of fruits and vegetables are protective against OPC & $80(51 \%)$ & $77(49 \%)$ \\
\hline & Elderly people are more likely to get OPC & $53(34 \%)$ & $104(66 \%)$ \\
\hline & $\mathrm{HPV}$ is associated with OPC & $36(23 \%)$ & $121(77 \%)$ \\
\hline \multirow[t]{4}{*}{ Clinical presentation } & Oral cancer may present as a non-healing ulcer & $77(49 \%)$ & $80(51 \%)$ \\
\hline & Oral cancer may present as a red patch & $29(19 \%)$ & $128(81 \%)$ \\
\hline & Oral cancer may present as a white patch & $35(22 \%)$ & $122(78 \%)$ \\
\hline & Oral cancer may present as a lump in the neck & $46(30 \%)$ & $110(70 \%)$ \\
\hline
\end{tabular}


media (newspapers, television, and radio) play a sizeable role being the leading source of information. It was also evident that dentist has been the second highest source of information (Table 4).

Questions were asked to ascertain the respondents' consumption of tobacco and alcohol. Table 5 summarises the habit status of those who are aware and not aware of OPC and PMODs. Sixty two percent $(n=185)$ of the respondents has indicated that they have smoked tobacco in their lifetime of which $25.3 \%(n=76)$ were current smokers. Among the current smokers the prevalence was higher among females (55.3\%) than males (44.7\%). In terms of alcohol consumption $71 \%(n=213)$ of the respondents indicated that they consume alcohol. There was no statistically significant difference on the awareness among those who smoke, consume alcohol and those who do.

Of those who were aware of oral cancer, $92 \%$ agreed or strongly agreed that smoking is a strong risk factor for OPC. Similarly a relatively high proportion of the population agreed or strongly agreed that tobacco chewing (84\%), tobacco chewing with areca nut $(68 \%)$, chewing areca nut alone $(51 \%)$ and exposure to actinic radiation $(71 \%)$ are risk factors. However, the result for heavy alcohol drinking, advancing age, and HPV infection was found to be relatively poor with proportions $33 \%, 34 \%$, and $23 \%$ respectively. Contrary to this only $51 \%$ indicated that eating fresh fruits and vegetables is protective against OPC. Knowledge on the clinical presentation of oral cancer was also found to be poor (Table 6).

\section{Discussion}

Strategies at population level are pivotal in prevention and early detection of any cancer which would reduce morbidity, morality and overall medical costs at individual as well as national level. This is particularly highly pertinent for oral and pharyngeal cancers especially because of easy access for screening to detect cancer and its lesions and associated risk factors are well established (Speight et al., 1992; Sankaranarayanan et al., 2005). Early detection of oral cancer is the most effective means to improve survival and to reduce morbidity, disfigurement, treatment duration and associated costs (Scott et al., 2008). Delay in diagnosis has been considered in the recent past as a significant factor which compromise the survival and worsening the treatment outcome (Scott et al., 2008; Gomez et al., 2010). Diagnostic delay has been interpreted as the elapsed time from the first symptom or sign until the definitive diagnosis is established (Gomez et al., 2010). This includes (i) patient delay: the period between the patient first noticing a sign or symptom and their first consultation with a health care professional; (ii) professional/provider delay: the period from the patient's first consultation with the health care provider and the time at which the definitive diagnosis is established (Hollows et al., 2000; Kerdpon and Sriplung, 2001; Gomez et al., 2010). The probability that patients present at an advanced stage of the tumour is $30 \%$ higher due to delay in diagnosis (Gomez et al., 2009). Gravity of patients' initial symptom interpretation and knowledge of oral cancer have been identified as significant factors for the duration of such delay (Scott et al., 2008). Therefore, a high level of public awareness on OPC and PMODs is of utmost importance for the individuals to present early to health care facilities.

This study highlights an alarming lack of awareness on OPC/PMODs among the Dental Hospital attending population in far North Queensland. Just over half $(52.3 \%)$ of the respondents were aware of oral cancer and the awareness was even worse for PMODs (19.0\%). A reasonably higher level of awareness was reported in a comparable hospital based sample in Western Australia (Park et al., 2011). Comparatively much higher levels of awareness have been reported from some highly prevalent countries of oral cancer such as India and Sri Lanka (Ariyawardana and Vithanaaracchi, 2005; Amarasinghe et al., 2010; Agrsawal et al., 2012).

Ariyawardana and Vitanaarachchi (2005) reported in their hospital based study that over $90 \%$ were aware of oral cancer and the figure for PMODs was 45 . Higher prevalence of oral cancer in that population and the displayed oral cancer education material such as posters, pamphlets etc. in public hospitals into which the general public has free access may be contributory for this high level of awareness. Similar features could be found in India as well. Amarasinghe et al., 2010 reported comparable results for awareness on OPC in their community based study in rural Sri Lanka. However, this study reported significantly low level (23.0\%) of public awareness on PMODs. Warnakulasuriya et al., 1999 reported alarming lack of public awareness on oral cancer in the UK. They reported in comparison to lung cancer of which the awareness was $97 \%$ only $56 \%$ of the participants of the survey were aware of oral cancer. Relatively low prevalence of oral cancer the use may have contributed to this result. This reason may also be valid for the low awareness on oral cancer and PMODs reported in our study.

Respondents with a higher level of education were the most aware of OPC signifying the impact of formal education on health awareness. This finding is compatible with other studies (Ariyawardana and Vitanaarachchi, 2005; Amarasinghe et al., 2010; Park et al., 2011; Agrawal et al., 2012). Mass media plays a pivotal role in making the general public aware on oral cancer (Ariyawardana and Vitanaarachchi, 2005; Amarasinghe et al., 2010; Park et al., 2011; Agrawal et al., 2012). The present study also confirmed this finding by being the most common source of knowledge for both OPC and PMODs (66.8\% and $52.6 \%$ respectively). Interestingly a number of awareness studies reported that the role played by dentists or other health care professionals are secondary (Ariyawardana and Vitanaarachchi, 2005; Amarasinghe et al., 2010; Park et al., 2011; Agrawal et al., 2012). Our study also has testified this. Possible explanations as to why dentists are playing a lesser influential role than mass media in conveying OPC/ PMODs awareness could be the limited patient attendance or accessibility to dentists and deficiencies in knowledge among dental professionals. Joint statement from the British Society for Oral Medicine (BSOM) and Cancer Research UK (CRUK) stressed the need for improved professional awareness and knowledge of OPC/PMODs 
Awareness and Knowledge of Oral Cancer and Potentially Malignant Oral Disorders among Dental Patients in Queensland

and suggested that oral cancer detection should be a highly recommended Continuing Professional Development topic (Kirby and Scully, 2013). Horowitz et al., 2000 in a survey among general dental practitioners found only $25 \%$ of them strongly agreed that they were adequately trained in providing oral cancer examinations. This highlights the fact that improvement of the knowledge of dentists on OPC/PMODs would increase the likelihood that a dentist will be a leading source of passing knowledge to their patients.

Knowledge of the risk factors among the general public is one of the most important parameters for successful prevention of oral cancer in the community. In the present study we found that, $92 \%$ of the aware respondents of OPC/PMODs were able to identify tobacco smoking as a strong risk factor while only $52 \%$ identified heavy alcohol as a risk factor. Contrary to this, Park et al., 2011 in their study based in Western Australia found that only $42 \%$ and $5 \%$ of patients were able to identify tobacco and alcohol respectively as risk factors for OPC.

The present study found level of education was the most significant socio-demographic factor affecting patients' risk factor knowledge; participants educated at graduate level or higher displayed an overall greater level of awareness of OPC/PMODs.

At early stages of the disease oral cancer is asymptomatic and hence the affected individuals do not seek treatment. Therefore, knowledge on the signs of oral cancer is of paramount importance. Self-examination of the oral mucosa has been considered an effective method of detecting asymptomatic early disease (Peacock et al., 2008). For effective self-examination of the oral mucosa and identification one should be well aware of the signs of oral cancer. The present study revealed that the knowledge on the signs of oral cancer was poor in that only below $50 \%$ were aware of different presentations of cancer in the mouth. Park et al.(2011) in their study in Western Australia also found compatible results in that $49 \%$ of the participants did not know any signs or symptoms of oral cancer.

Study limitations: The population studied was patients attending JCU Dental and there is a selection bias that prevents the results from being generalizable to the entire FNQ population. Since the majority of participants opted not to indicate their ethnicity for this survey, ethnicity was excluded from the analysis. Furthermore, the questionnaire was designed only in English and this has prevented non-English speaking individuals being participated for this study.

In summary, we investigated on the awareness on OPC and PMODs in far north Queensland population and to the best of our knowledge this has hitherto not been investigated. The study revealed an alarming lack of awareness towards oral cancer and PMODs which requires to be readily addressed. Public health promotion, education initiatives and awareness campaigns should be implemented on a local and national scale to increase levels of OPC/PMODs awareness and knowledge. This will also help to facilitate early detection through approaches such as patient self-examination.

\section{Acknowledgements}

The authors would like to express their sincere graditude to all the participants, to James Cook University for bearing the printing costs of the questionnaire and to JCU dental staff for their support and encouragement in conducting the surve.

\section{References}

Agrawal M, Pandey S, Jain S, Maitin S (2012). Oral cancer awareness of general public in Gorakhpur City, India. Asian Pac J Cancer Prev, 13, 5195-9.

Amarasinghe H K, Usgodaarachchi US, Johnson N W, Lalloo R, Warnakulasuriys S (2010). Public awareness of oral cancer, of oral potentially malignant disorders and their risk factors in some rural populations in Sri Lanka. Community Dent Oral Epidemiol, 38, 540-8.

Ariyawardana A, Johnson NW (2013). Trends of lip, oral cavity and oropharyngeal cancers in Australia 1982-2008: overall good news but with rising rates in the oropharynx. $B M C$ Cancer, 13, 333.

Ariyawardana A, Vithanaarachchi N (2005). Awareness of oral cancer and precancer among patients attending a Hospital in Sri Lanka. Asian Pac J Cancer Prev, 6, 58-61.

Australian Beaurau of Statistics. Available at: http://www.abs. gov.au/AUSSTATS/abs@.nsf/DetailsPage/3303.02011?O penDocument.

Bettendorf O, Piffko J, Bankfalvi A (2004). Prognostic and predictive factors in oral squamous cell cancer: important tools for planning individual therapy? Oral Oncol, 40,110-9.

Chandu A, Sun K C V, DeSilva R N, Smith A C H (2005). The assessment of quality of life in patients who have undergone surgery for oral cancer: A preliminary report. $J$ Oral Maxillofac Surg, 63, 1606-12.

Chandu A, Smith A C H, Rogers S N (2006). Health related quality of life in oral cancer: a review. J Oral Maxillofac Surg, 64, 495-502.

Ferlay J, Soerjomataram I, Ervik M, et al (2013). GLOBOCAN 2012 v1 .0, Cancer incidence and mortality worldwide: IARC cancer base No. 11 [Internet].Lyon, France: International agency for research on cancer; 2013. Accessed on 25 January 2014.

Ferlay J, Shin H, Bray F, et al (2010). Estimates of worldwide burden of cancer in 2008: GLOBOCAN 2008. Int J Cancer, 127, 2893-917.

Gomez I, Seoane J, Varlea-Centelles PI, Diz P, Takkouche B (2009). Is diagnostic delay related to advanced-stage oral cancer? Eur J Oral Sci, 117, 541-6.

Gomez I, Warnakulasuriya S, Varlea-Centelles PI, et al (2010). Is early diagnosis of oral cancer a feasible objective? Who is to blame for diagnostic delay? Oral Dis, 16, 333-42.

Hollows P, Mcandrew PG, Perini MG (2000). Delays in the referral and treatment of oral squamous cell carcinoma. $\mathrm{Br}$ Dent $J, \mathbf{1 8 8}, 262-5$.

Horowitz AM, Drury TF, Goodman HS, Yellowitz J A (2000). Oral pharyngeal cancer prevention and early detection: dentists' opinions and practices. J American Dent Assoc, 21, 452-62.

Kerdpon D, Sriplung H (2001). Factors related to delay in diagnosis of oral squamous cell carcinoma in southern Thailand. Oral Oncol, 37, 127-31.

Kirby J, Scully C (2013). Statement on mouth cancer diagnosis and prevention. UK: British Society for oral medicine and cancer research. [Accessed 13 October 2014].

Marur S, D'Souza G, Westra WH, Forastiere AA (2010). HPV- 
associated head and neck cancer: a virus-related cancer epidemic. Lancet Oncol, 11, 781-9.

Organization for Economic Co-operation and Development (2011). OECD Health Data. Paris: OECD 2011. [Accessed 24 Sept 2014].

Park J H, Slack-Smith L, Smith A, et al (2011). Knowledge and perceptions regarding oral and pharyngeal carcinoma among adult dental patients. Aust Dent J, 56, 284-9.

Peacock Z S, Pogrel M A, Schmidt B L (2008). Exploring the reasons for delay in treatment of oral cancer. $J$ American Dent Assoc, 139, 1346-52.

Rogers SN, Brown JS, Woolgar JA, et al (2009). Survival following primary surgery for oral cancer. Oral Oncol, 45, 201-11.

Sankaranarayanan R, Ramadas K, Thomas G, et al (2005). Effect of screening on oral cancer mortality in Kerala, India: a cluster randomised controlled trial. Lancet, 365, 1927-33.

Sargaran K, Murtomma H, Safavi S MR, Vehkalahti MM, Teronen O (2008). Survival after diagnosis of cancer of the oral cavity. Br J Oral Maccofac Surg, 46, 187-91.

Scott SE, McGurk M, Grunfeld EA (2008). Patient delay for potentially malignant oral symptoms. Eur J Oral Sci, 116, 141-47.

Speight PM, Zakrzewska J, Downer MC (1992). Screening for oral cancer and precancer. Eur J Cancer B Oral Oncol, 28, 45-8.

Warnakulasuriya S (1999). An alarming lack of public awareness towards oral cancer. Brit Dent J, 187, 319-22.

Warnakulasuriya S (2009). Global epidemiology of oropharyngeal cancer. Oral Oncol, 45, 309-16.

Zini A, Czerninski R, Sgan-Cohen H D (2010). Oral cancer over four decades: epidemiology, trends, histology and survival by anatomical sites. J Oral Pathol Med, 39, 299-305. 